\title{
Vascular plant species richness on wetland remnants is determined by both area and habitat heterogeneity
}

\author{
Jianmin Shi $\cdot$ Keming Ma $\cdot$ Jifeng Wang $\cdot$ Jingzhu Zhao $\cdot$ \\ Kate He
}

Received: 18 March 2009/Accepted: 1 December 2009/Published online: 15 December 2009

(C) Springer Science+Business Media B.V. 2009

\begin{abstract}
There is an ongoing ecological debate on whether area per se or habitat heterogeneity is the main driver for species richness. The wetland remnants in the Sanjiang Plain, NE China harbor a high biodiversity and play an important role for local ecosystems. Fifty-one wetland remnants were sampled to examine the effect of area and habitat heterogeneity on vascular plant species richness. Number of community types, elevation, water heterogeneity and soil resource heterogeneity were employed as habitat heterogeneity variables, but only water heterogeneity was identified as the proper surrogate for habitat heterogeneity. Compared with the classic species-area model, the choros model achieved better fitness when water heterogeneity and elevation were employed as habitat heterogeneity variables. Nevertheless, elevation was poorly correlated with species richness. It suggests, without a comprehensive analysis of habitat heterogeneity variables, the choros model might result in a misleading result. In this study, species richness was significantly influenced by water heterogeneity, area and number of community types. Water heterogeneity and area both controlled the number of community types, and they were the two main determinants of species richness. As area was significantly and
\end{abstract}

J. Shi $\cdot$ K. Ma · J. Zhao

Institute of Urban Environment, Chinese Academy of Sciences, Jimei Road 1799,

361021 Xiamen, China

J. Shi

College of Forestry, Jiangxi Agricultural University, Zhimin Road 1066,

330045 Nanchang, China

K. Ma (ه)

State Key Laboratory of Urban and Regional Ecology, Research Center for Eco-Environmental

Sciences, Chinese Academy of Sciences, P.O. Box 2871, 100085 Beijing, China

e-mail: mkm@ @rcees.ac.cn

J. Wang

Institute of Natural Resource and Ecology, Heilongjiang Academy of Sciences,

Harping Road 103, 150040 Harbin, China

K. He

Department of Biological Sciences, Murray State University, Murray, KY 42071, USA 
positively correlated with water heterogeneity, the variance in species richness was mainly related to the mutual effect of area and water heterogeneity. The results of this study confirmed that the relationship between the area per se hypothesis and the habitat heterogeneity hypothesis was conjunct rather than mutually exclusive. In addition, it is critical that both area and water heterogeneity should be taken into account for biodiversity conservation and management in wetland remnants.

Keywords Species-area relationship - The choros model · Habitat heterogeneity · Species richness - Wetland remnant - The Sanjiang Plain · NE China

$\begin{array}{ll}\text { Abbreviations } \\ \text { NCT } & \text { Number of community types } \\ \text { CV } & \text { Coefficient of variation } \\ \text { WC } & \text { Water condition } \\ \text { SQI } & \text { Soil quality index } \\ \text { EC } & \text { Electrical conductivity } \\ \text { OM } & \text { Organic matter } \\ \text { TN } & \text { Total nitrogen } \\ \text { AN } & \text { Available nitrogen } \\ \text { TP } & \text { Total phosphorus } \\ \text { AP } & \text { Available phosphorus } \\ \text { TK } & \text { Total potassium } \\ \text { AK } & \text { Available potassium }\end{array}$

\section{Introduction}

As predictions of the loss of global biodiversity grow increasingly pessimistic, identifying the factors that determine species richness has become a hot topic (Willis and Whittaker 2002). In the last decades, a long-running discussion was focused on the area per se hypothesis and the habitat heterogeneity hypothesis as the drivers of species richness (Kallimanis et al. 2008). Many studies were conducted to discern the contribution of area and habitat heterogeneity to species richness, but the results were inconsistent. Some studies showed that area was the only driving force for species richness (e.g., Kitchener et al. 1982; Krauss et al. 2004; Kreft et al. 2008) while others showed that habitat diversity was the main driving force (e.g., Kitchener et al. 1980; Brose 2001; Báldi 2008) and still others showed that both of them played an important role in species richness (e.g., Kohn and Walsh 1994; Triantis et al. 2005; Kallimanis et al. 2008). In fact, the role of area and habitat heterogeneity to species richness varies in different taxonomic groups (e.g., Kitchener et al. 1980; Kitchener et al. 1982; Ricklefs and Lovette 1999) and "island" types (e.g., Nilsson et al. 1988; Brose 2001; Krauss et al. 2004; Panitsa et al. 2006).

Other than the definite and easily measured parameter (area), the proper measures of habitat heterogeneity are likely to differ from one type of organism to another (Ricklefs and Lovette 1999). Ricklefs and Lovette (1999) summarized the commonly employed measures of habitat heterogeneity, including elevation, topographic diversity, number of community types (NCT), soil types, structural habitat types, quantified vegetation structure and plant species richness for animal species. The selection of proper surrogates for habitat 
heterogeneity should be based on detailed analysis on characteristics of the focal taxon and its environmental factors (Panitsa et al. 2006).

Besides the commonly used measures mentioned earlier, soil resource as an important composition of the habitat, is being considered more and more often in plant species richness studies (e.g., Stevens and Carson 2002; Davies et al. 2005; Zhou et al. 2008). Variation in soil nutrients might be an especially important type of heterogeneity in plant communities, and different plant species are expected to sort into patches of differing soil fertility (Reynolds et al. 2007). Therefore, soil resource heterogeneity was considered as a strong driver of plant species coexistence and community diversity (Tilman 1988). Currently, studies on the effect of soil resource heterogeneity on plant species have reported conflicting results: some studies showed a positive effect (e.g., Davies et al. 2005; Marchand and Houle 2006; Zhou et al. 2008), and others found no significant effect (e.g., Stevens and Carson 2002; Wijesinghe et al. 2005; Reynolds et al. 2007) or even negative effect (Kleb and Wilson 1997). These inconsistent patterns could be the result of different processes operating at different spatial scales (Davies et al. 2005).

While the definition of habitat heterogeneity is difficult to give (Triantis et al. 2003), various measures have been employed as surrogate for it. However, there are few studies taking the common measures and soil resource heterogeneity together into account to discern their effect on species richness and screen surrogates for habitat heterogeneity.

Recently, a new model (the choros model) proposed by Triantis et al. (2003) mathematically unified area per se and the habitat heterogeneity hypotheses. The choros model $\left(\mathrm{S}=\mathrm{cK}^{\mathrm{z}}\right)$ was an extension of the classical species-area relationship $\left(\mathrm{S}=\mathrm{cA}^{\mathrm{z}}\right)$ (Arrhenius 1921). The term choros (K) was simply the total area (A) of a region multiplied by the number of habitats $(\mathrm{H})$ within that region: $\mathrm{K}=\mathrm{A} \times \mathrm{H}$. Employing proper measures of habitat heterogeneity, the choros model usually achieves a better fitness than the Arrhenius model (Triantis et al. 2003, 2005; Panitsa et al. 2006; Duarte et al. 2008), especially in explaining species richness patterns on small islands (Triantis et al. 2005).

Therefore, in this work, we focus on the relationships among species richness, area and habitat heterogeneity on wetland remnants in the Sanjiang Plain, northeast China, and aim to achieve the following objectives: (1) to distinguish the contribution of area and habitat heterogeneity to vascular plant species richness; (2) to screen proper surrogates for habitat heterogeneity from the commonly used measures and soil resource heterogeneity variables; (3) to test and evaluate the effectiveness of the choros model; and (4) to provide suggestions for biodiversity conservation and management of the wetland remnants.

\section{Materials and methods}

\section{Study region}

The Sanjiang Plain, located in the east of Heilongjiang province, is the largest freshwater wetlands in China (Liu et al. 2000). However, the original wetland ecosystem of the Sanjiang Plain has been seriously altered by intensive agricultural activity since the 1950 s. A vast area of marsh had been fragmented into a patchy mosaic of isolated remnants as a result of anthropogenic activity. By 2000, the wetland area only accounted for $7.7 \%$ of the total area (10.89 $\times 10^{6}$ ha) of the Sanjiang Plain (Li et al. 2002).

Our study area is located in Bielahong River basin, a typical region in the Sanjiang Plain, which covers an area of $43.34 \times 10^{4}$ ha. The mean annual precipitation in this area is around $600 \mathrm{~mm}$ and the mean annual temperature is $1.91^{\circ} \mathrm{C}$. Water and soil in wetlands 
are completely frozen from October to next April and begin to melt in late April. The vegetation on the wetland remnants is mainly composed of herbaceous species, and reaches the peak of plant species richness and vegetation cover in summer. Usually, the center of remnant has standing water, while the edges are moist to try. There is an obvious water gradient from the center to the edge of wetland remnant, thus, it shows an annular zonation pattern in the structure of vegetation.

Site area, elevation and vascular flora

The study sites were selected by means of aerial photographs and field visits to ensure their representation and even distribution in the study area as much as possible (Fig. 1). Wetland remnants grazed were excluded from the investigation leaving a total of 51 sampled sites. Using the GPS receiver (GPS 72, GARMIN), site's geographical coordinates, elevation and area were measured (Table 1).

The survey method for the complete vascular plant species in a site followed the method of Kohn and Wash (1994) with walking through the site as systematically as possible. According to the vegetation classifications of China, different community types were defined by the dominant species in the community (Wu 1980). Thus, the number of community types (NCT) was counted during the field investigation. In two growing seasons (summer 2007 and 2008), repeated surveys were carried out for each site, a total list of plant species per study site was achieved by compiling the two datasets.

Habitat heterogeneity variables

Due to the water gradient and annular zonation pattern of vegetation, a transect was placed from the remnant center to edge to detect the heterogeneity of water condition (WC) and soil resource during the vascular flora survey. Along the transect, $1 \mathrm{~m} \times 1 \mathrm{~m}$ quadrats were placed at $15 \mathrm{~m}$ intervals from the site center, and a quadrat was placed on the edge regardless of the interval. If there were community types at the site that were not sampled

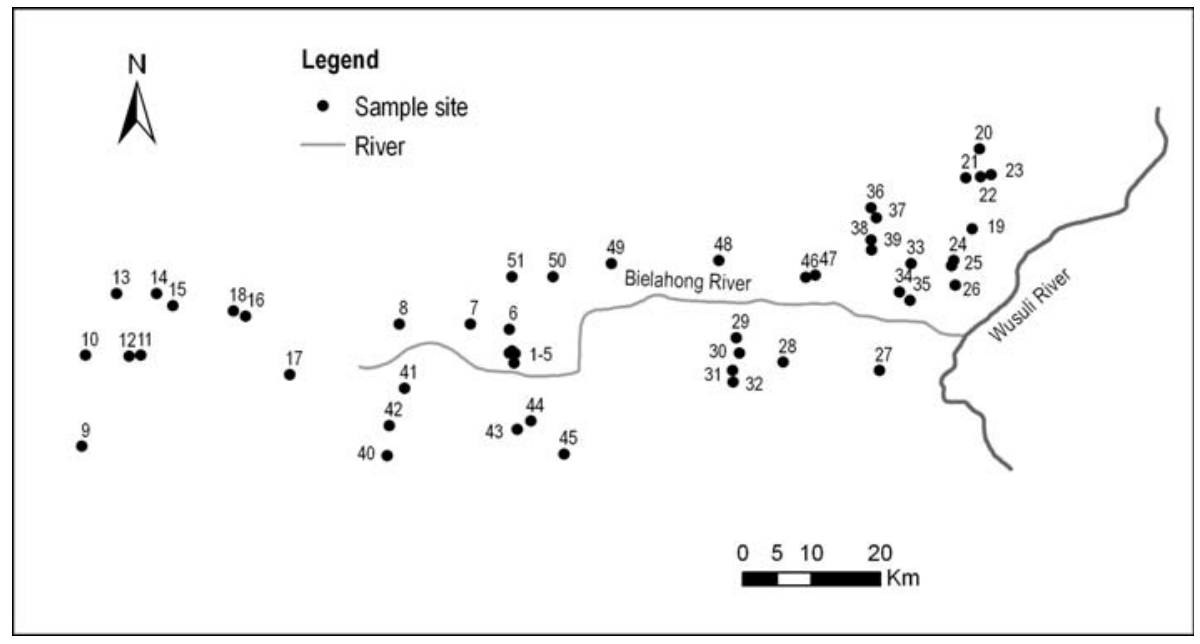

Fig. 1 The distribution of sample sites 


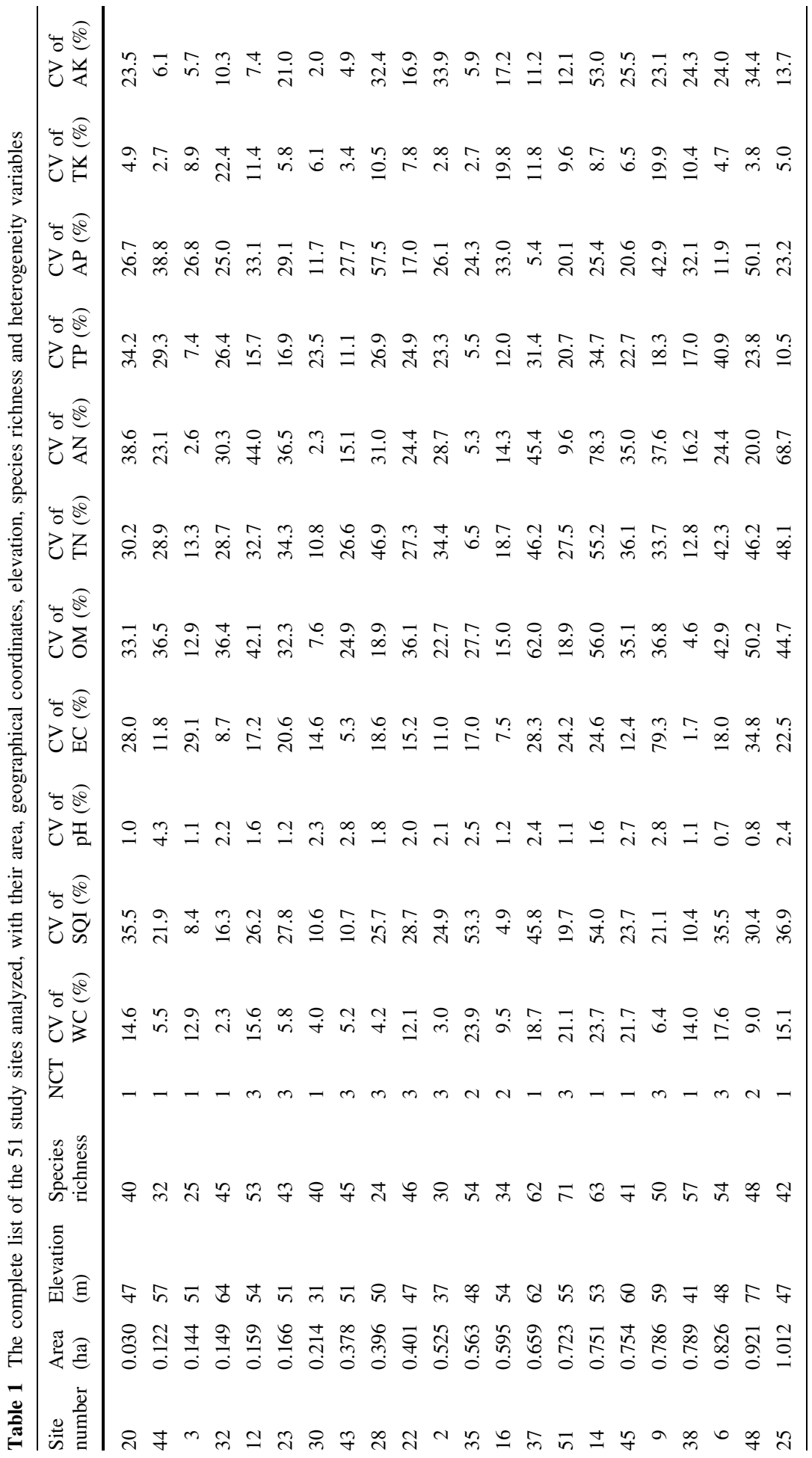




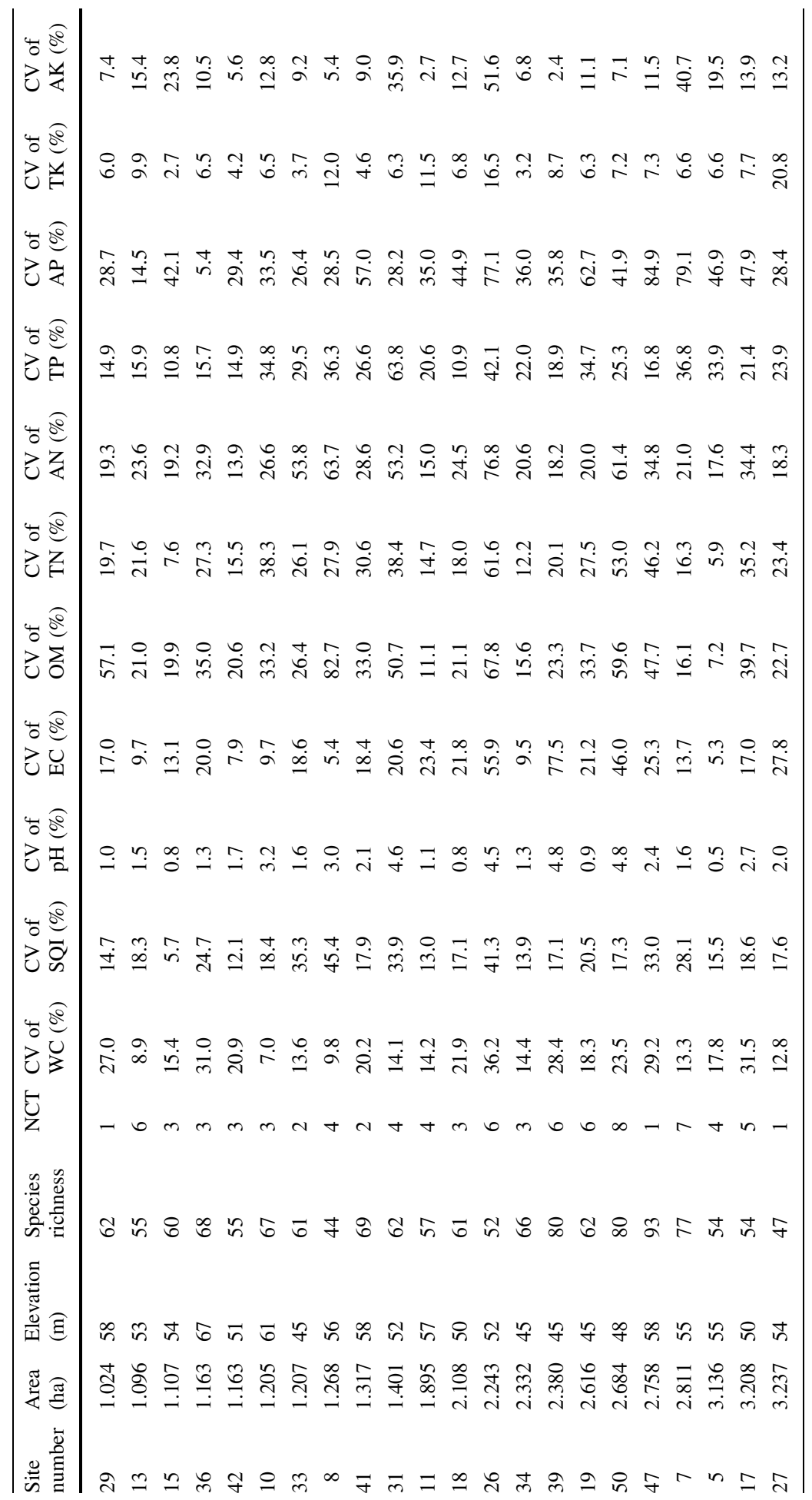




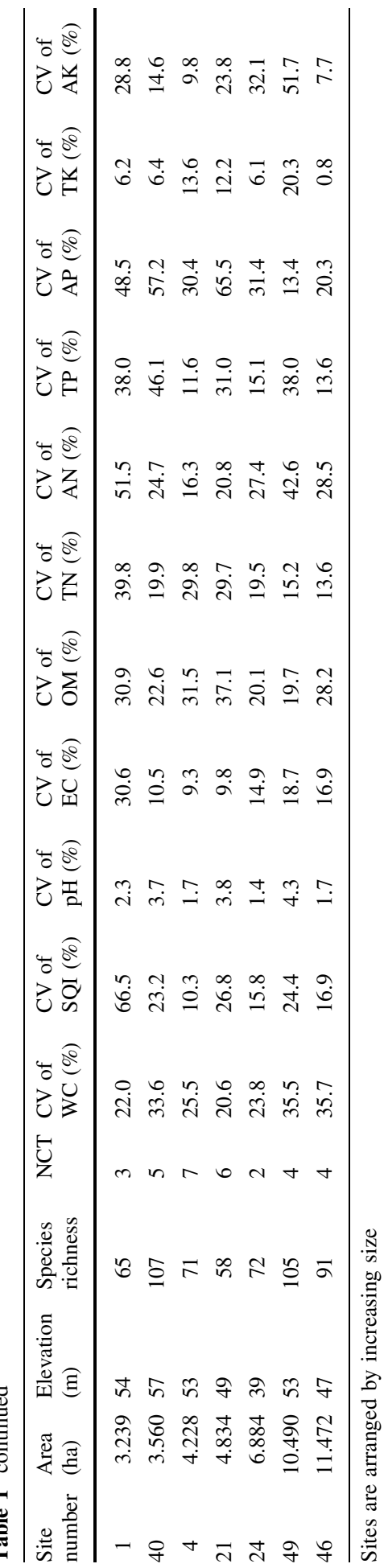


on the transect, additional quadrats would be placed in their centers respectively. All quadrats' species compositions were investigated.

To minimize the effect of weather on water condition among sites, the water condition measurements were completed in five days without rainfall. Soil moisture of quadrat without standing water was determined with $\mathrm{HH} 2$ moisture meter (Delta-T Device Ltd.), and water depth was measured by a conventional steel measuring tape in the quadrat with standing water.

Soil samples were collected with a depth of $30 \mathrm{~cm}$ from three locations distributed triangularly near the quadrat center. Three soil samples within the same quadrat were pooled as a single composite sample for subsequent processing. After air-drying, the soil samples were cleared of roots and organic debris and ground to pass 2-mm and 100 mesh sieves respectively for subsequent chemical analysis. Soil chemical properties were analyzed using standard soil test methods (Lu 1999). The soil measurements included acidity $(\mathrm{pH})$, electrical conductivity (EC), organic matter $(\mathrm{OM})$, total nitrogen $(\mathrm{TN})$, available nitrogen (AN), total phosphorus (TP), available phosphorus (AP), total potassium (TK) and available potassium (AK). Soil $\mathrm{pH}$ and $\mathrm{EC}$ were measured in a 1:2.5 soil:water solution with pH-meter (Delta 320, Mettler-Toledo) and EC-meter (Delta 326, Mettler-Toledo) respectively. OM was determined by the $\mathrm{K}_{2} \mathrm{Cr}_{2} \mathrm{O}_{7}$ titration method after digestion. TN was measured by the semi-micro Kjeldahl digestion procedure. AN was determined by the Cornfield method (alkaline hydrolysable nitrogen). TP and TK were digested with $\mathrm{H}_{2} \mathrm{SO}_{4}$ plus $\mathrm{HClO}_{4}$. AP was extracted with $0.5 \mathrm{~mol} \cdot \mathrm{L}^{-1} \mathrm{NaHCO}_{3}$ solution $(\mathrm{pH} 8.5)$, and $\mathrm{AK}$ was extracted with $1.0 \mathrm{~mol} \cdot \mathrm{L}^{-1} \mathrm{CH}_{3} \mathrm{COONH}_{4}$ solution (pH 7.0). The content of TP, AP, TK and AK was measured by ultraviolet spectrophotometer (UV-1700, Shimadzu).

\section{Statistical analyses}

The hydrology of wetland is a dynamic process, and a small number of measurements might not reflect its actual condition adequately. Calibration is an effective method to estimate the water condition, including soil moisture, soil $\mathrm{pF}$ value, groundwater level and surface water, and it has been used widely and successfully in applied plant ecology (e.g., ter Braak and Gremmen 1987; Goslee et al. 1997; Schaffers and Sýkora 2000; Magee and Kentula 2005). Moreover, the species indicator values calibrated with field measurement data should achieve better statistic estimation (Diekmann 2003).

In the study sites, there are five distinct water ecotypes including hydrophytes, helophytes, hygrophytes, mesophytes and xerophytes grown along the water gradient from the center to edge, thus it is beneficial to calibrate water condition. Based on species presence/ absence data of quadrats, we estimated the water condition by using weighted averaging species indicator values which were calibrated with field measurements (Diekmann and Falkengren-Grerup 1998; Diekmann 2003). Let $r_{i j}$ be the occurrence of species $i$ in quadrat $j$, and $x_{i}$ be the hydrological indicator value of species $i$. Then the water condition of quadrat $j\left(\mathrm{WC}_{j}\right)$ was calculated:

$$
\mathrm{WC}_{j}=\sum_{i=1}^{n}\left(r_{i j} \times x_{i}\right) / \sum_{i=1}^{n} r_{i j}
$$

where $x_{i}$ is the optimum solution of the regression between $\mathrm{WC}$ and the hydrological measurement. The detailed calculating processes for $x_{i}$ were as below: First, hydrological indicator value of species $(x)$ was classified in five grades according to the five water ecotypes; second, quadrat WC values calculated by Eq 1 were regressed on the quadrat 
measurement values of soil moisture and water depth respectively; thus the optimum solutions $\left(x_{i}\right)$ were calculated from the optimum regression equations.

In order to reflect the overall soil nutrient condition, we integrated $\mathrm{pH}, \mathrm{EC}, \mathrm{OM}, \mathrm{TN}$, AN, TP, AP, TK and AK into a soil quality index (SQI). Based on the assumption that different nutrients have different roles in maintaining soil quality, the SQI was calculated by the following equation (Fu et al. 2004; Masto et al. 2008):

$$
\mathrm{SQI}=\sum_{i=1}^{n} W_{i} \times S_{i}
$$

where $W_{i}$ and $S_{i}$ were the weight and membership value of soil quality factor $i$ respectively. $W_{i}$ was determined by principal component analysis (PCA). Based on the cumulative percentage of principal soil quality components and the values of component capacity score coefficient, $W_{i}$ was calculated as:

$$
W_{i}=C_{i} / \sum_{i=1}^{n}\left(C_{i}\right)
$$

where $C_{i}$ is the component capacity score coefficient of soil quality factor $i$.The membership values $\left(S_{i}\right)$ were calculated as either ascending or descending functions (Eqs. 4 and 5). An ascending function was used for a soil quality factor with positive component capacity score, and vice versa.

$$
\begin{aligned}
& S_{i}=\left(x_{i j}-x_{i \min }\right) /\left(x_{i \max }-x_{i \min }\right) \\
& S_{i}=\left(x_{i \max }-x_{i j}\right) /\left(x_{i \max }-x_{i \min }\right)
\end{aligned}
$$

where $x_{i j}$ was the observed value $j$ of soil quality factor $i ; x_{i \max }$ and $x_{i \min }$ were the maximum and minimum value of the soil quality factor $i$ respectively.

The coefficient of variation (CV) is usually employed as a measure of heterogeneity (e.g., Marchand and Houle 2006; Reynolds et al. 2007; Zhou et al. 2008). Using all quadrats' values in each site, the coefficient of variation (CV) for water condition and soil quality factors was calculated, and we used them to denote the water heterogeneity and soil resource heterogeneity respectively (see Table 1). Moreover, CV of WC and CV of SQI were used as habitat heterogeneity variables.

The Arrhenius model $\left(\mathrm{S}=\mathrm{cA}^{\mathrm{z}}\right)$ and the choros model $\left(\mathrm{S}=\mathrm{c}(\mathrm{A} \times \mathrm{H})^{\mathrm{z}}\right)$ were used to test the species-area relationship respectively, and we used their conventional logarithmic transformations to estimate the equation parameters. Measures of habitat heterogeneity, including elevation, NCT, CV of WC and CV of SQI, were employed as the term of H in the choros model. For the comparison of the two models, the $R^{2}$ value and Akaike's information criterion (AIC) were used as measures of goodness-of-fit. We calculated the difference of the AIC value between the Arrhenius model and the choros model $\left(\Delta \mathrm{AIC}=\mathrm{AIC}_{(\text {Arrhenius model })}-\mathrm{AIC}_{(\text {choros }}\right.$ model $)$, and a positive difference indicates that the choros model gives a better fit to the data (Triantis et al. 2003). If the choros model achieved a better fitness than the Arrhenius model, the significance of the difference between their slopes was tested by a Student's test (Zar 1984).

All variables were checked for normality and linearity, and $\log _{10}$-transformed when it was necessary. Simple correlation (Pearson correlation) analysis was used to detect the relationships among species richness, site area and the heterogeneity variables. Simple regression and stepwise regression were used to check for the effects of site area and the 
habitat heterogeneity variables on species richness. To partition the contributions of the independent variables entered into stepwise regression to species richness, we used the F statistics for type III sums of squares to assess the unique statistical contributions of each independent variable to the variation in the dependent variable, taking into account the correlations among the independent variables (Ricklefs and Lovette 1999).

The calibration procedure was performed by Matlab 7.1, and others statistical analyses were performed using SPSS 11.0 for Windows.

\section{Results}

Species-area relationship and the choros model

The 51 sites covered area ranging from 0.03 up to 11.47 ha with an average size of 1.94 ha, and included from one to eight community types (Table 1). Sites elevations varied from 31 to $77 \mathrm{~m}$, and the average was $52 \mathrm{~m}$. Total number of vascular plant species recorded was 266. The representative families were Compositae (42 species), Cyperaceae (27 species), Gramineae (21 species), Leguminosae (15 species), Polygonaceae (15 species) and Ranunculaceae (11 species), and species of the six families accounted for $49.25 \%$ of the total species. Site species richness ranged from 24 to 107 species with an average of 58 species.

There were big differences in sites' water heterogeneity (as indicated by CV of WC), the minimum was only $2.3 \%$, whereas the maximum was up to $36.2 \%$, and the average was $17.5 \%$ (Table 1). Except $\mathrm{CV}$ of $\mathrm{pH}$ and $\mathrm{CV}$ of $\mathrm{TK}$, the variation range of soil resource heterogeneity among sites was also quite broad (all above 50\%). On the contrary, the value and variation range of $\mathrm{CV}$ of $\mathrm{pH}$ and $\mathrm{CV}$ of $\mathrm{TK}$ were relatively low. The $\mathrm{CV}$ of $\mathrm{pH}$ was less than $5 \%$, and the maximum of CV of TK was only $22.4 \%$ (Table 1 ).

The classical species-area relationship could be depicted as $\mathrm{S}=54.325^{*} \mathrm{~A}^{0.189}$ $\left(R^{2}=0.494\right)$ for the 51 sites. Using elevation, NCT, CV of WC and CV of SQI as habitat heterogeneity variables, only the choros model $1\left(R^{2}=0.508, \Delta \mathrm{AIC}=1.37\right)$ and the choros model $3\left(R^{2}=0.586, \Delta \mathrm{AIC}=10.22\right)$ achieve a better fitness than the Arrhenius model (Table 2). This indicated that elevation and CV of WC might be proper surrogates for habitat heterogeneity.

Compared with the Arrhenius model, all the choros models dropped more or less in the slope (z-value) except the choros model 1. As to the two higher explanatory models, their slopes did not differ significantly from that of the Arrhenius model $(t=0.029, P>0.05$ for the choros model $1 ; t=1.367, P>0.05$ for the choros model 3 ).

Table 2 Slope, intercept and $R^{2}$ value of the Arrhenius model and the Choros models

\begin{tabular}{lllll}
\hline Model & Slope & Intercept & $R^{2}$ & $\Delta$ AIC \\
\hline Arrhenius model & 0.189 & 1.735 & $0.494 * * *$ & $/$ \\
Choros model 1 $(\mathrm{H}=$ elevation $)$ & 0.190 & 1.410 & $0.508^{* * *}$ & 1.37 \\
Choros model 2 $(\mathrm{H}=\mathrm{NCT})$ & 0.131 & 1.683 & $0.446^{* * *}$ & -4.67 \\
Choros model 3 $(\mathrm{H}=\mathrm{CV}$ of WC) & 0.146 & 1.858 & $0.586^{* * *}$ & 10.22 \\
Choros model 4 $(\mathrm{H}=\mathrm{CV}$ of SQI) & 0.168 & 1.849 & $0.471^{* * *}$ & -2.24 \\
\hline
\end{tabular}

$\mathrm{H}$ means the habitat heterogeneity variable, $* * * P$ value $<0.001$ 
Relationships among species richness, area and habitat heterogeneity

Species richness was strong positively associated with CV of WC, site area and NCT, and there were no significant correlations between species richness and elevation and between species richness and soil resource heterogeneity (Table 3; Fig. 2). The $R^{2}$ values of the regression of area and $\mathrm{CV}$ of $\mathrm{WC}$ on species richness were almost equal, about $50 \%$, and they were both higher than that of NCT $\left(R^{2}=0.158\right.$, Fig. 2$)$.

Site area was significantly and positively correlated with CV of WC and NCT, but was poorly correlated with elevation $(r=-0.015, P>0.05)$. Moreover, correlation between site area and soil resource heterogeneity was consistent with the correlation between species richness and soil resource heterogeneity, which was not significant.

Elevation did not significantly influence the variables of habitat heterogeneity or soil resource heterogeneity, except $\mathrm{CV}$ of $\mathrm{OM}(r=0.390, P<0.01)$. NCT was closely correlated with water heterogeneity $\mathrm{CV}$ of $\mathrm{WC}(r=0.303, P<0.05)$ and one soil resource heterogeneity variable, CV of AP $(r=0.316, P<0.05)$. Regardless of whether single variables of soil resource heterogeneity or the integrated variable of soil fertility heterogeneity (CV of SQI) was used in the correlation analysis, their correlation coefficients with water heterogeneity (CV of WC) were not significant (Table 3).

It is worth noting that the correlation between species richness and elevation was very weak ( $r=0.092, P>0.05$ ), while the choros model 1 (elevation as habitat heterogeneity variable) showed a better fitness than that of the Arrhenius model. The disagreement between the correlation analysis and the choros model performance implied that the choros model might lead to a misleading result in a special case.

Although there were thirteen variables for habitat heterogeneity or soil resource heterogeneity and two variables (CV of WC and NCT) of them were significantly and positively correlated with species richness, only CV of WC together with site area was entered

Table 3 Correlations among species richness, area and heterogeneity variables in the 51 sites

\begin{tabular}{|c|c|c|c|c|c|c|}
\hline & Species richness & Area & Elevation & NCT & $\mathrm{CV}$ of $\mathrm{WC}$ & CV of SQI \\
\hline Area & $0.702 * *$ & 1.000 & & & & \\
\hline Elevation & 0.092 & -0.015 & 1.000 & & & \\
\hline NCT & $0.398 * *$ & $0.522 * *$ & -0.089 & 1.000 & & \\
\hline $\mathrm{CV}$ of $\mathrm{WC}$ & $0.711 * *$ & $0.627 * *$ & 0.040 & $0.303^{*}$ & 1.000 & \\
\hline $\mathrm{CV}$ of SQI & 0.028 & -0.033 & 0.118 & -0.096 & 0.152 & 1.000 \\
\hline $\mathrm{CV}$ of $\mathrm{pH}$ & 0.203 & 0.154 & -0.029 & 0.240 & 0.161 & 0.230 \\
\hline $\mathrm{CV}$ of $\mathrm{EC}$ & 0.123 & 0.037 & 0.138 & 0.097 & 0.261 & $0.311 *$ \\
\hline $\mathrm{CV}$ of $\mathrm{OM}$ & 0.061 & -0.011 & $0.390 * *$ & 0.079 & 0.203 & $0.538 * *$ \\
\hline $\mathrm{CV}$ of $\mathrm{TN}$ & -0.093 & -0.111 & 0.263 & 0.035 & -0.025 & $0.436 * *$ \\
\hline $\mathrm{CV}$ of $\mathrm{AN}$ & 0.207 & 0.201 & 0.228 & 0.150 & 0.203 & $0.494 * *$ \\
\hline $\mathrm{CV}$ of TP & 0.189 & 0.137 & 0.106 & 0.218 & 0.007 & $0.363 * *$ \\
\hline $\mathrm{CV}$ of $\mathrm{AP}$ & 0.080 & 0.236 & 0.021 & $0.316^{*}$ & 0.036 & -0.061 \\
\hline $\mathrm{CV}$ of $\mathrm{TK}$ & -0.059 & 0.013 & 0.217 & 0.109 & -0.042 & -0.032 \\
\hline $\mathrm{CV}$ of $\mathrm{AK}$ & 0.031 & 0.152 & 0.134 & 0.039 & 0.078 & $0.339 *$ \\
\hline
\end{tabular}

\footnotetext{
* Correlation is significant at the 0.05 level (2-tailed)
}

** Correlation is significant at the 0.01 level (2-tailed) 
Fig. 2 Regressions of site area (a), CV of WC (b) and number of community types (NCT) (c) on species richness
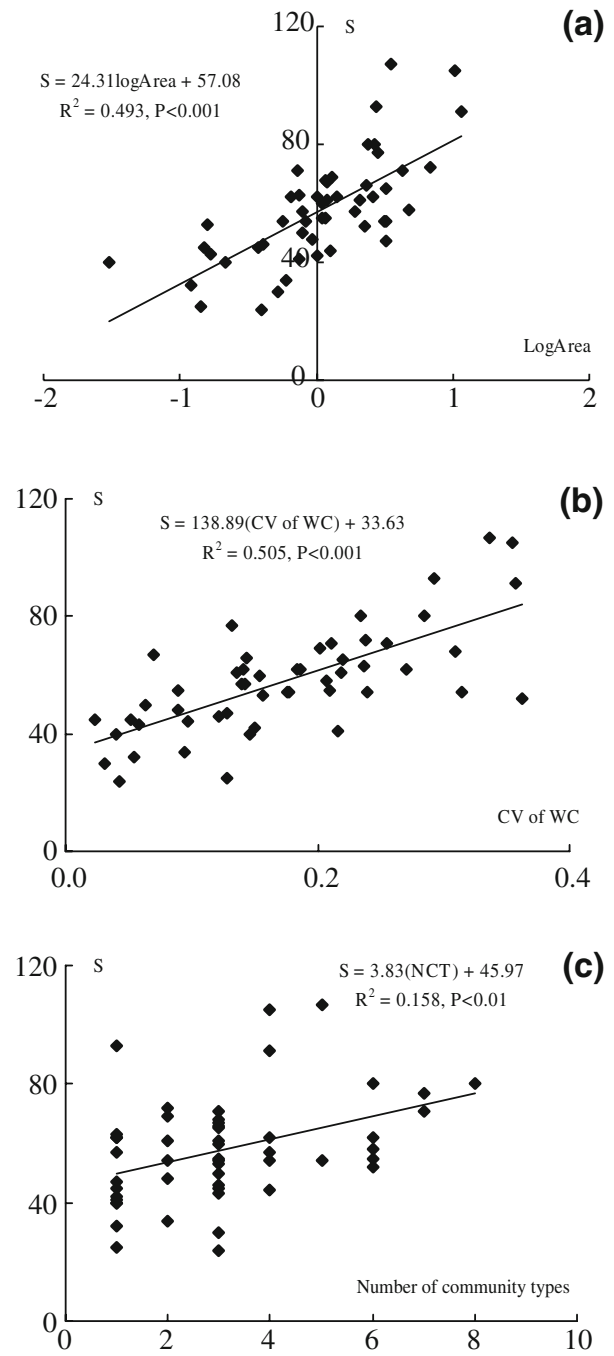

into the stepwise regression: Species $=42.175+87.116 \log \mathrm{CV}$ of $\mathrm{WC}+14.644 \log$ Area $\left(R^{2}=0.614, F=38.098, P<0.001\right)$. NCT was excluded from the stepwise regression owing to its high correlation with site area $(r=0.522, P<0.001)$ and $\mathrm{CV}$ of WC $(r=0.303, P<0.05)$, although it was a strong predictor variable.

According to the stepwise regression, area and CV of WC accounted for $61.4 \%$ of the species richness variation, which was higher than any univariable regression (Fig. 2). The standardized partial regression coefficient of CV of WC and area were 0.446 and 0.423 respectively, and both of them were significant with $P<0.001$.

Contributions of area and habitat heterogeneity to species richness

Based on the stepwise regression, four components' contribution to variance in species richness were partitioned: one uniquely related to area, one uniquely related to $\mathrm{CV}$ of $\mathrm{WC}$, a third related to correlated variation in area and $\mathrm{CV}$ of WC, and the unexplained (Fig. 3). 
Fig. 3 Proportion of variance in species richness related uniquely to area, uniquely to $\mathrm{CV}$ of $\mathrm{WC}$, to both area and CV of WC, and unexplained. The values in bars were their contributions to variance in species richness

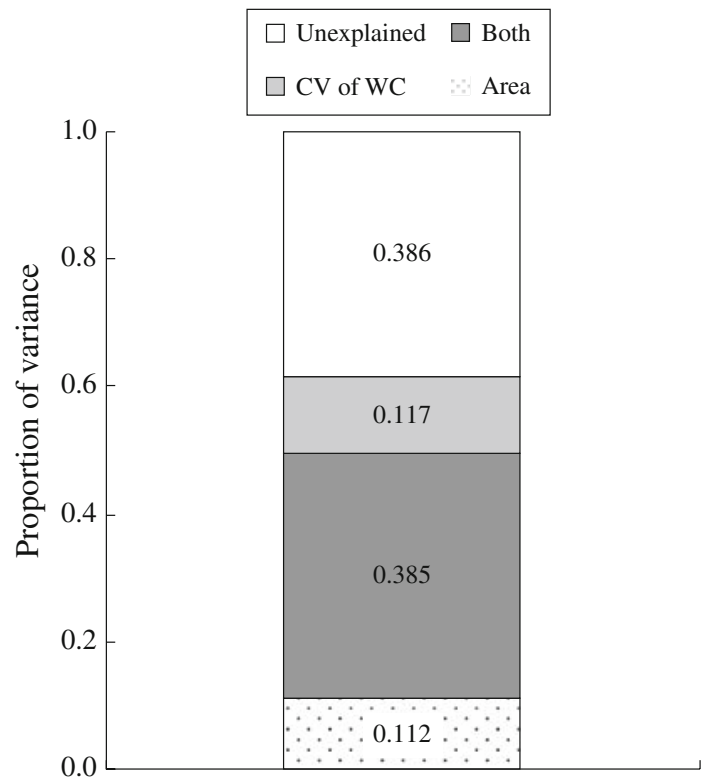

Variation in species richness related to the correlation between area and CV of WC $(38.5 \%)$ was more than the sum of uniquely related to area $(11.2 \%)$ and uniquely related to $\mathrm{CV}$ of WC $(11.7 \%)$. It indicated that the variance in species richness was mainly caused by mutual effect of area and water heterogeneity (as indicated by $\mathrm{CV}$ of WC).

\section{Discussion}

Surrogate for habitat heterogeneity in the wetland remnants

A proper surrogate for habitat heterogeneity is quite difficult to define (e.g., Kohn and Wash 1994; Triantis et al. 2005; Panitsa et al. 2006), while elevation and NCT have been commonly used in previous studies (Ricklefs and Lovette 1999). Panitsa et al. (2006) and Kreft et al. (2008) proved that elevation is an important factor influencing plant species richness. However, the effect of elevation was not statistically significant in this work (Table 3). The topography of the Sanjiang Plain is quite low, with an elevation variation range of $46 \mathrm{~m}$, thus, it might result in little influence of elevation on plant species richness. Although NCT was significantly and positively correlated with species richness, it was excluded from the stepwise regression for its high correlation with site area and CV of WC (Table 3), the same as the woody plant richness study performed by Nilsson et al. (1988).

Ricklefs (1977) hypothesized that local heterogeneity in soil properties and surface microenvironment could enhance tree species diversity. Indeed, many studies have verified the fact that increasing soil resource heterogeneity increases species richness (e.g., Davies et al. 2005; Zhou et al. 2008). In this work, not only single soil resource heterogeneity variables but also the integrated soil fertility heterogeneity showed non-significant correlations with species richness (Table 3). Similar results have also been reported by other ecologists (Stevens and Carson 2002; Wijesinghe et al. 2005; Reynolds et al. 2007). 
Reynolds et al. (2007) attributed the absence of a significant correlation to the presence of clonal species, which dominated in the vegetation and decreased species richness by restraining other species' growth. Physiological integration permits the redistribution of resources internally from ramets in high quality patches to those in low quality patches, allowing clonal plants to perform well when resources are heterogeneous, thus the clonal species might modulate the effects of resource heterogeneity on plant species diversity (Reynolds et al. 2007). The vegetations of the wetland remnants in the Sanjiang Plain are dominated by clonal species such as Deyeuxia angustifolia, D. neglecta, Glyceria spiculosa, Carex lasiocarpa, C. meyeriana, C. pseudocuraica, etc. Therefore, we also suggest that the presence of dominate clonal species might be one of the reasons resulting in no effect of soil resource heterogeneity on species richness.

Variation in soil hydrology could be a basis for species richness in plant communities (Silvertown et al. 1999). Pollock et al. (1998) and Brose (2001) confirmed the water heterogeneity is an important factor that affects plant species richness in riparian wetlands and temporary wetlands. According to the traditional gradient theory (Whittaker 1975), the increase in water heterogeneity implies an increase in niches, allowing more species to coexist, especially for some habitat specialists. Thus, water heterogeneity value in the wetland remnants represents the niche range affording for species to coexist. As we expected, CV of WC significantly and positively influenced species richness (Table 3), and it is the unique variable of habitat heterogeneity entered in the stepwise regression on species richness. It indicated that $\mathrm{CV}$ of $\mathrm{WC}$ is a proper habitat heterogeneity variable. Based on the above analyses, the habitat heterogeneity variables defined in this work are not suited to serve as surrogates for habitat heterogeneity except CV of WC.

The choros Model performance and the $z$-value

Recently, the choros model was successfully used in ecology studies with a better fit than the Arrhenius model (Triantis et al. 2003, 2005; Panitsa et al. 2006; Duarte et al. 2008), and we tested it by employing different habitat heterogeneity variables in this work. Except elevation, other habitat heterogeneity variables employed in the choros models achieved results consistent with the simple correlation analysis and the stepwise regression (Tables 2,3): the choros model using a proper habitat heterogeneity variable (CV of WC) gave a higher $R^{2}$ value and a lower AIC value than that of the Arrhenius model. In this case, the effectiveness of the choros model supported further.

Nevertheless, elevation was weakly correlated with species richness, while the choros model 1 had a better fitness than the Arrhenius model (Tables 2,3). The result contradicted the model proposers' statement: a habitat heterogeneity measure that is not informed by the natural history of the focal taxon could reduce the fitness of the choros model (Triantis et al. 2003, 2005; Panitsa et al. 2006). Mathematically, because the term choros (K) is a product of the total area $(\mathrm{A})$ and a habitat heterogeneity variable $(\mathrm{H})$, there is the possibility that an unrelated $\mathrm{H}$ variable could result in a higher $R^{2}$ in the choros model. Although Triantis et al. (2003) stressed that a proper habitat heterogeneity variable is necessary in the application of the choros model, we know that defining the proper habitat heterogeneity measure is a difficult work (e.g., Ricklefs and Lovette 1999; Panitsa et al. 2006). Therefore, we contended that besides the analysis on the natural history of the taxa, classical statistical analyses should be used to verify the result of the choros model. Otherwise, a misleading result may be obtained during the choros model performing.

The $z$-value reflects the isolation of island group and habitat heterogeneity, and the continental areas show much lower $z$-values, usually between 0.12 and 0.17 , because of a 
higher immigration rate of transient species on continents (MacArthur and Wilson 1967). Rosenzweig (1995) classified the $z$-value in three categories: between biogeographical provinces, within biogeographical provinces and of islands or isolated habitat patches, and the typical value was $0.5-1,0.1-0.2$ and $0.2-0.5$, respectively. Brose (2001) and Krauss et al. (2004) reported a $z$-value of 0.15 and 0.11 in temporary wetlands and calcareous grasslands respectively. Consisted with those results for land "island", the $z$-value of the Arrhenius model $(z=0.189)$ and the choros models $(z=0.131-0.190)$ in this work all fit the category of within biogeographical provinces and generally support the suggestions about continental areas' z-value (MacArthur and Wilson 1967).

Prevalent hypotheses suggest that different slopes of species-area curve are influenced by different environmental conditions or different degrees of isolation (Rosenzweig 1995). Kallimanis et al. (2008) confirmed that the $z$-value is a linear function of habitat heterogeneity. Moreover, Harner and Harper (1976) noted: areas that had uniformly distributed species that were also represented by many individuals would have low $z$-values. In this work, the wetland remnants used to be a united and continuous wetland before the intensive agricultural development, and their species compositions were similar. Therefore, the similar species composition might be one of the main factors resulting in low $z$-value.

\section{Mechanisms for species richness}

It is known that factors affecting species richness are usually correlated with area (Ricklefs and Lovette 1999), thus, distinguishing between the direct and indirect effects of area on species richness has been proven difficult (e.g., Kohn and Walsh 1994; Rosenzweig 1995; Ricklefs and Lovette 1999). Moreover, a new model (the choros model) unifying the area per se hypothesis and the habitat heterogeneity hypothesis was proposed to test speciesarea relationship, and a better fitness was usually achieved (Triantis et al. 2003, 2005; Panitsa et al. 2006; Duarte et al. 2008). After a long discussion on the dichotomy between area per se hypothesis (Preston 1960; MacArthur and Wilson 1967) and habitat heterogeneity hypothesis (Williams 1964), now there is a tendency to regard the two mechanisms jointly rather than mutually exclusive (e.g., Kohn and Walsh 1994; Ricklefs and Lovette 1999; Triantis et al. 2003, 2005; Kallimanis et al. 2008).

In this work, the relationship among the three intercorrelated variables (area, CV of WC and species richness) is very close (Table 3; Fig. 3). The large sites with high water heterogeneity could support wide niche extents for more species to coexist, including habitat generalists and habitat specialists. On the contrary, the small sites usually could not support high water heterogeneity: there were seven small sites with $\mathrm{CV}$ of $\mathrm{WC}<6 \%$ (Table 1). Thus, the limited area and low water heterogeneity only allow specific habitat specialists and fewer habitat generalists to grow. Furthermore, the low water heterogeneity may intensify interspecific competition. According to our field survey, many typical wetland species were disappeared in small sites, such as Habenaria sagittifera, Platanthera hologlottis, Gentiana manshurica, Ranunculus amurensis, etc. As area and habitat heterogeneity are not independent of each other, plant species richness on the wetland remnants is controlled by both area and habitat heterogeneity.

Suggestions for biodiversity conservation and management

The wetland remnants support many species and play an important role in the maintenance of biodiversity in the Sanjiang Plain. The total number of surveyed vascular plant species (266) accounts for $14.9 \%$ of the Heilongjiang Province flora (Guo and Xing 1990), while 
the study area is only $0.9 \%$ of Heilongjiang Province. Since the most lands have been transformed into agricultural land and species have no place to live except the remnants, these wetland remnants are a very important and indispensable supplement to the nature reserves in biodiversity conservation in the local region.

Kohn and Wash (1994) stated that the interrelationships among the area, habitat heterogeneity and species richness might have potent implications for biodiversity conservation and management. In this work, vascular plant species richness significantly increased with an increase in area and water heterogeneity, while water heterogeneity was controlled by site area. Therefore, our study results indicate that site area and water heterogeneity are crucial factors for plant species richness in wetland remnants, and large wetland remnants have more conservation values. Some large wetland remnants with high water heterogeneity are prior protecting objects, because they provide habitats and resources not only for plant species but also for waterfowl, fish and other creatures.

Acknowledgments The study was supported by the National Natural Science Foundation of China (No. 40671182). We thank two anonymous reviewers for their valuable comments on the manuscript.

\section{References}

Arrhenius O (1921) Species and area. J Ecol 9:95-99

Báldi A (2008) Habitat heterogeneity overrides the species-area relationship. J Biogeogr 35:675-681

Brose U (2001) Relative importance of isolation, area and habitat heterogeneity for vascular plant species richness of temporary wetlands in east-German farmland. Ecography 24:722-730

Davies KF, Chesson P, Harrison S, Inouye BD, Melbourne BA, Rice KJ (2005) Spatial heterogeneity explains the scale dependence of the native-exotic diversity relationship. Ecology 86:1602-1610

Diekmann M (2003) Species indicator values as an important tool in applied plant ecology—a review. Basic Appl Ecol 4:493-506

Diekmann M, Falkengren-Grerup U (1998) A new species index for forest vascular plants: development of functional indices based on mineralization rates of various forms of soil nitrogen. J Ecol 86:269-283

Duarte MC, Rego F, Romeiras MM, Moreira I (2008) Plant species richness in the Cape Verde Islandseco-geographical determinants. Biodivers Conserv 17:453-466

Fu B, Liu S, Chen L, LÜ Y, Qiu J (2004) Soil quality regime in relation to land cover and slope position across a highly modified slope landscape. Ecol Res 19:111-118

Goslee SC, Brooks RP, Cole CA (1997) Plants as indicators of water source. Plant Ecol 131:199-206

Guo G, Xing Q (1990) Flora of Heilongjiang province. Heilongjiang People's Publishing House, Harbin (in Chinese)

Harner RF, Harper KT (1976) The role of area, heterogeneity, and favorability in plant species diversity of pinyon-juniper ecosystems. Ecology 57:1254-1263

Kallimanis AS, Mazaris AD, Tzanopoulos J, Halley JM, Pantis JD, Sgardelis SP (2008) How does habitat diversity affect the species-area relationship? Glob Ecol Biogeogr 17:532-538

Kitchener DJ, Chapman A, Dell J, Muir BG, Palmer M (1980) Lizard assemblage and reserve size and structure in the Western Australian wheatbelt some implications for conservation. Biol Conserv $17: 25-62$

Kitchener DJ, Dell J, Muir BG, Palmer M (1982) Birds in Western Australian wheatbelt reserves-implication for conservation. Biol Conserv 22:127-163

Kleb H, Wilson S (1997) Vegetation effects on soil resource heterogeneity in prairie and forest. Am Nat 150:283-298

Kohn DD, Walsh DM (1994) Plant species richness-the effect of island size and habitat diversity. J Ecol $82: 367-377$

Krauss J, Klein AM, Steffan-Dewenter I, Tscharntke T (2004) Effects of habitat area, isolation, and landscape diversity on plant species richness of calcareous grasslands. Biodivers Conserv 13:1427-1439

Kreft H, Jetz W, Mutke J, Kier G, Barthlott W (2008) Global diversity of island floras from a macroecological perspective. Ecol Lett 11:116-127

Li Y, Zhang Y, Zhang S (2002) The landscape pattern and ecological effect of the marsh changes in the Sanjiang Plain. Sci Geogr Sin 22:677-682 (in Chinese) 
Liu H, Lu X, Liu Z (2000) Landscape planning and ecology construction of wetland comprehensive protected area system in the Sanjiang Plain. J Environ Sci 12:361-366

$\mathrm{Lu}$ R (1999) Methods for soil and agriculture chemistry analysis. Chinese Agricultural Science and Technology Press, Beijing (in Chinese)

MacArthur RH, Wilson EO (1967) The theory of island biogeography. Princeton University Press, NJ

Magee TK, Kentula ME (2005) Response of wetland plant species to hydrologic conditions. Wetlands Ecol Manage 13:163-181

Marchand P, Houle G (2006) Spatial patterns of plant species richness along a forest edge: what are their determinants? For Ecol Manag 223:113-124

Masto RE, Chhonkar PK, Purakayastha TJ, Patra AK, Singh D (2008) Soil quality indices for evaluation of long-term land use and soil management practices in semi-arid sub-tropical India. Land Degrad Dev 19:516-529

Nilsson SG, Bengtsson J, Ås S (1988) Habitat diversity or area per se? Species richness of woody plants, carabid beetles and land snails on islands. J Anim Ecol 57:685-704

Panitsa M, Tzanoudakis D, Triantis KA, Sfenthourakis S (2006) Patterns of species richness on very small islands: the plants of the Aegean archipelago. J Biogeogr 33:1223-1234

Pollock MM, Naiman RJ, Hanley TA (1998) Plant species richness in riparian wetlands-a test of biodiversity theory. Ecology 79:94-105

Preston FW (1960) Time and space and the variation of species. Ecology 41:611-627

Reynolds HL, Mittelbach GG, Darcy-Hall TL, Houseman GR, Gross KL (2007) No effect of varying soil resource heterogeneity on plant species richness in a low fertility grassland. J Ecol 95:723-733

Ricklefs RE (1977) Environmental heterogeneity and plant species diversity: a hypothesis. Am Nat 111:376-381

Ricklefs RE, Lovette IJ (1999) The roles of island area per se and habitat diversity in the species-area relationships of four Lesser Antillean faunal groups. J Anim Ecol 68:1142-1160

Rosenzweig ML (1995) Species diversity in space and time. Cambridge University Press, NY

Schaffers AP, Sýkora KV (2000) Reliability of Ellenberg indicator values for moisture, nitrogen and soil reaction: a comparison with field measurements. J Veg Sci 11:225-244

Silvertown J, Dodd ME, Gowing DJG, Mountford JO (1999) Hydrologically defined niches reveal a basis for species richness in plant communities. Nature 400:61-63

Stevens MHH, Carson WP (2002) Resource quantity, not resource heterogeneity, maintains plant diversity. Ecol Lett 5:420-426

ter Braak CJF, Gremmen NJM (1987) Ecological amplitudes of plant species and the internal consistency of Ellenberg's indicator values for moisture. Vegetatio 69:79-87

Tilman D (1988) Plant strategies and the dynamics and structure of plant communities. Princeton University Press, Princeton

Triantis KA, Mylonas M, Lika K, Vardinoyannis K (2003) A model for the species-area-habitat relationship. J Biogeogr 30:19-27

Triantis KA, Mylonas M, Weiser M, Lika K, Vardinoyannis K (2005) Species richness, habitat diversity and area: a case study based on land snails in Skyros archipelago (Aegean Sea, Greece). J Biogeogr 32:1727-1735

Whittaker RH (1975) Communities and ecosystems, 2nd edn. Macmillan, NY

Wijesinghe DK, John EA, Hutchings MJ (2005) Does pattern of soil resource heterogeneity determine plant community structure? An experimental investigation. J Ecol 93:99-112

Williams CB (1964) Patterns in the balance of nature. Academic Press, London

Willis KJ, Whittaker RJ (2002) Species diversity—scale matters. Nature 295:1245-1248

Wu Z (1980) Vegetation of China. Science Press, Beijing (in Chinese)

Zar HJ (1984) Biostatistical analysis, 2nd edn. Prentice Hall, NJ

Zhou Z, Sun OJ, Luo Z, Jin H, Chen Q, Han X (2008) Variation in small-scale spatial heterogeneity of soil properties and vegetation with different land use in semiarid grassland ecosystem. Plant Soil 310: $103-112$ 